AU/ACSC/99-212/1999-04

AIR COMMAND AND STAFF COLLEGE

AIR UNIVERSITY

\title{
THE BENEFITS OF SIMULATOR INTEGRATION TO AMC
}

\author{
by \\ Mark A. Thomas, Maj., USAF \\ A Research Report Submitted to the Faculty \\ In Partial Fulfillment of the Graduation Requirements
}

Advisor: Maj. Anthony J. Gould

Maxwell Air Force Base, Alabama

April 1999 


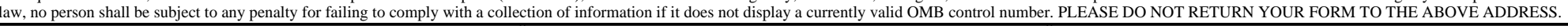
1. REPORT DATE (DD-MM-YYYY) 2. REPORT TYPE 01-04-1999 Thesis 3. DATES COVERED (FROM - TO) 4. TITLE AND SUBTITLE

The Benefits of Simulator Integration to AMC Unclassified

6. AUTHOR(S)

Thomas, Mark A. ; XX-XX-1999 to XX-Xx-1999

7. PERFORMING ORGANIZATION NAME AND ADDRESS

Air Command and Staff College

Maxwell AFB, AL36112

9. SPONSORING/MONITORING AGENCY NAME AND ADDRESS

5a. CONTRACT NUMBER

5b. GRANT NUMBER

5c. PROGRAM ELEMENT NUMBER

5d. PROJECT NUMBER

5e. TASK NUMBER

5f. WORK UNIT NUMBER

8. PERFORMING ORGANIZATION REPORT

NUMBER

10. SPONSOR/MONITOR'S ACRONYM(S)

11. SPONSOR/MONITOR'S REPORT

$\operatorname{NUMBER}(\mathrm{S})$

12. DISTRIBUTION/AVAILABILITY STATEMENT

APUBLIC RELEASE

\section{SUPPLEMENTARY NOTES}

14. ABSTRACT

The current military budget restrictions create a need to explore alternative ways of training aircrew members. The purpose of this paper is to examine the benefits of simulator integration in Air Mobility Command (AMC) as an alternative training method. The initial discussion is the mandate by the Undersecretary of Defense for Acquisition and Technology to convert all DoD simulators to High Level Architecture (HLA). Converting simulators to HLA enables them to interact seamlessly, providing crews the benefit of Distributive Mission Training (DMT). After presenting the current AMC flying hour and simulator program, an explanation and analysis is provided. Next, a notional flying time savings is proposed followed by the obstacles and advantages to substituting simulator time for actual flying time. Finally, the research concludes that not funding HLA/DMT in the FY00 POM was a mistake. There are a few technological obstacles that need to be solved before DMT will be fully functional. However, was consideration given to budget lead times of 5 to 7 years? This must be weighed against Moore?s Law which states that micro technology will double every 18 months at the same price. When the obstacles are solved, DMT promises to provide better, more efficient training at a significant cost reduction. Because DMT can provide better prepared crews for combat, the progress of DMT must be followed closely to determine if and when it becomes a viable training method.

15. SUBJECT TERMS

16. SECURITY CLASSIFICATION OF:

17. LIMITATION

OF ABSTRACT

Public Release

\begin{tabular}{|l|l}
$\begin{array}{l}\text { 18. } \\
\text { NUMBER } \\
\text { OF PAGES } \\
45\end{array}$ & $\begin{array}{l}\text { 19. NAME OF RESPONSIBLE PERSON } \\
\text { Fenster, Lynn } \\
\text { Ifenster@dtic.mil }\end{array}$ \\
& $\begin{array}{l}\text { 19b. TELEPHONE NUMBER } \\
\text { International Area Code } \\
\text { Area Code Telephone Number } \\
\text { 703767-9007 } \\
\text { DSN } \\
427-9007\end{array}$ \\
\hline
\end{tabular}




\section{Disclaimer}

The views expressed in this academic research paper are those of the author(s) and do not reflect the official policy or position of the US government or the Department of Defense. In accordance with Air Force Instruction 51-303, it is not copyrighted, but is the property of the United States government. 


\section{Contents}

Page

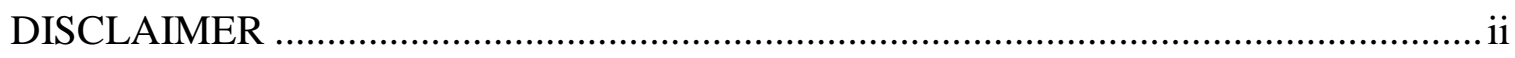

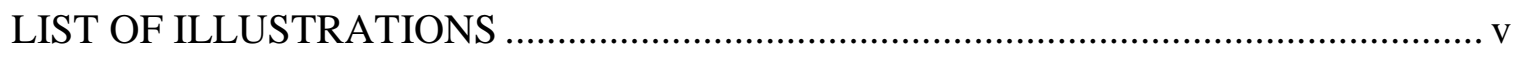

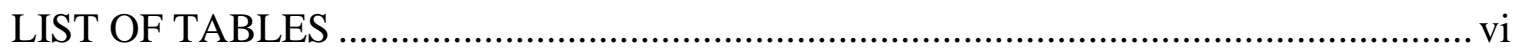

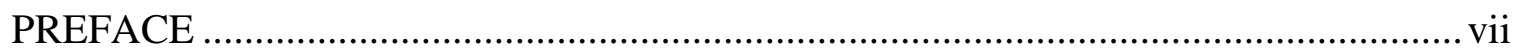

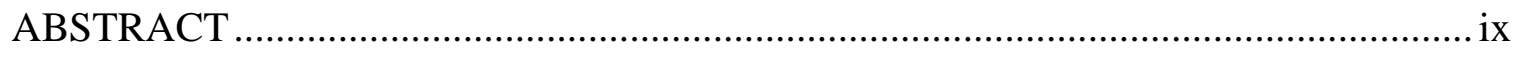

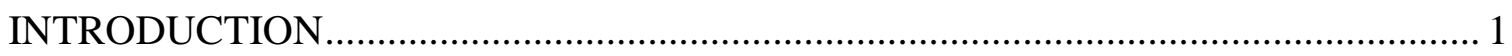

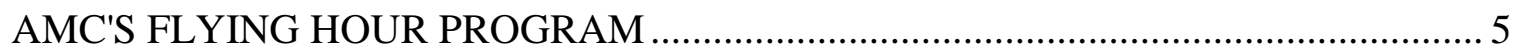

Transportation Working Capitol Fund.................................................................. 5

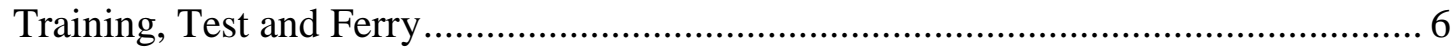

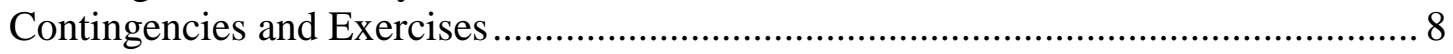

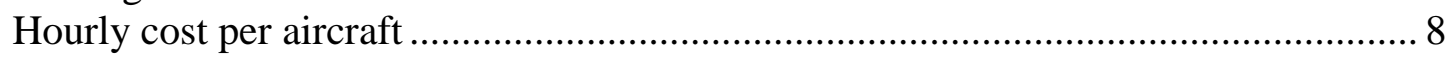

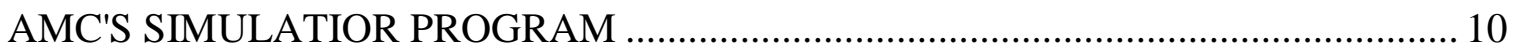

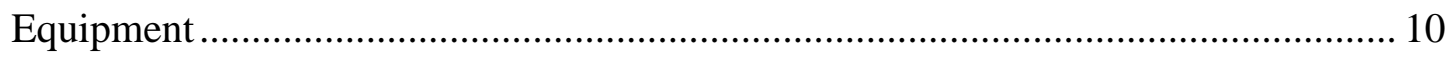

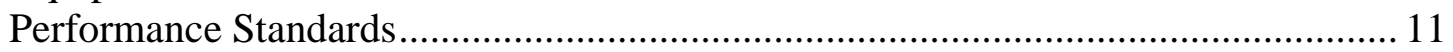

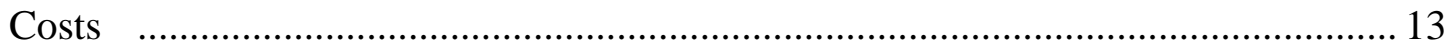

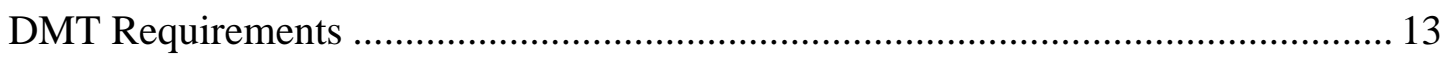

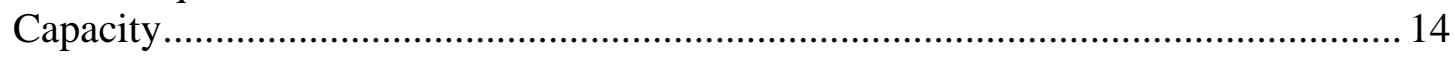

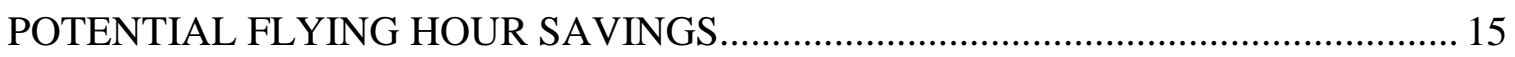

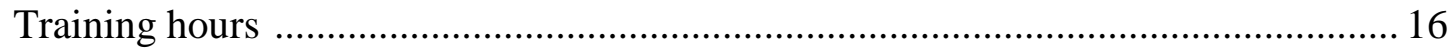

Potential areas of savings ................................................................................... 19

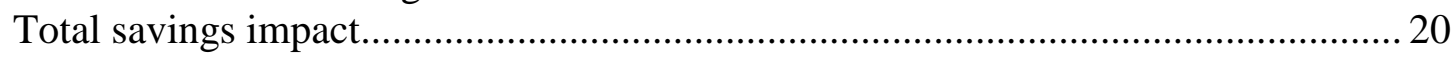

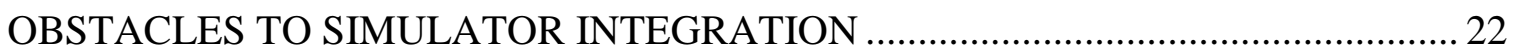

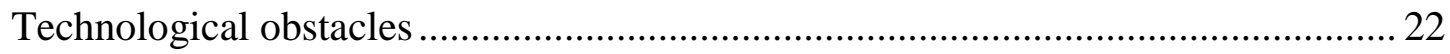

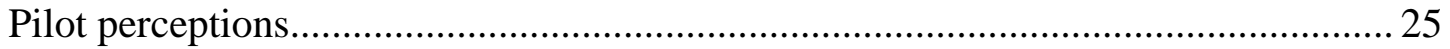


ADVANTAGES TO SIMULATOR INTEGRATION ........................................... 27

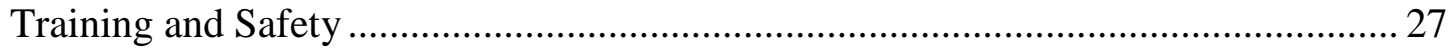

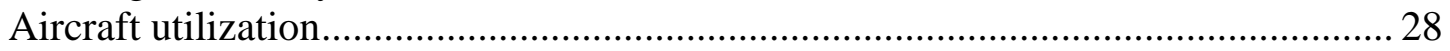

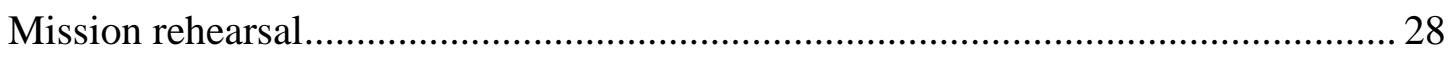

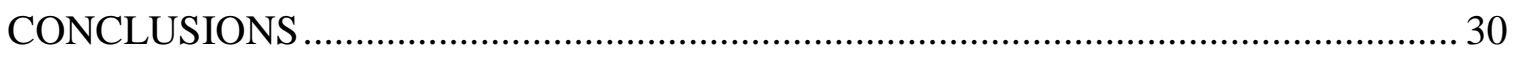

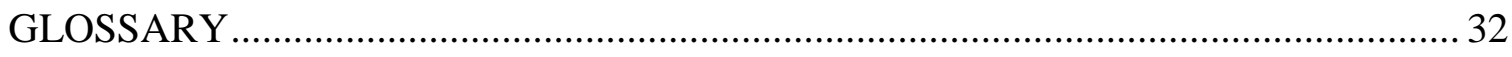

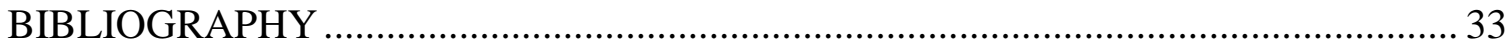




\section{Illustrations}

Page

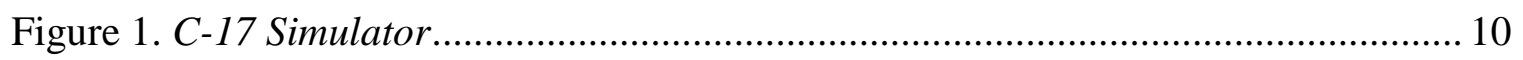




\section{Tables}

Page

Table 1 Flying Hour Costs for Continuation Training ............................................. 8

Table 2. FY00 Programmed Flying Hours ........................................................... 9

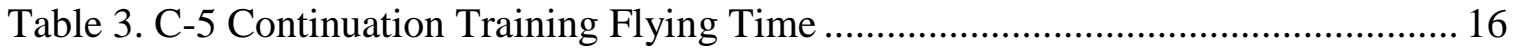

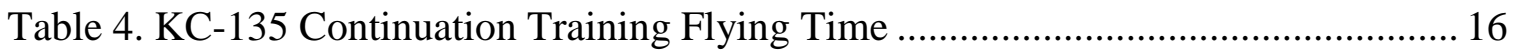

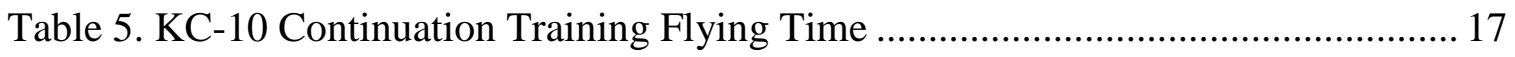

Table 6. C-17 Continuation Training Flying Time …............................................ 17

Table 7. Notional Flying Time Reductions ........................................................... 20 


\section{Preface}

The majority of my military career has been involved with training crewmembers to fly better, safer and more effectively. My recent past was spent working in the training section for the Director for Operations at HQ AMC. My first job in AMC/DOT was managing KC-135/KC-10 flying time. My next job was the Program Element Monitor (PEM) for Mobility Training Devices. It was in this job that I was placed in charge of the simulator upgrade program for AMC. Because of my selection for ACSC, I was only involved with the program for a very short amount of time. In that time I was given the challenge of programming, planning and funding a new program called Distributive Mission Training (DMT). While this program is still in it's infancy, DMT has the potential to be one of those "Military Technological Revolutions" that we discussed at ACSC. If the program works as advertised, the time, cost and safety benefits to all training will be revolutionized. DMT not only applies to aircrew members, but to all aspects of war training, such as the battle staff. However, there are several obstacles to overcome before DMT can be implemented. The purpose for this research was to explain how implementing DMT could benefit the training of AMC crews and explore the obstacles to integration. I hoped that I have adequately motivated and focus the reader on the status of the simulator program, where it could go, and what needs to be done if DMT is to be utilized. 
My research project couldn't have been accomplished without the help of the men and women of HQ AMC/DOT. Maj. Mark Nunn took over the PEM job, and he carries the responsibility of implementing this program. The Chief flying time program manager, Maj. Ken Olsen was extremely helpful with his flying time models. Mr. Dave Stahre, Mr. Denny Hughes and Mr. Jim Fell are the civilians that keep the simulation upgrade program on track. Lt. Col. Widincamp took over the leadership role from Lt. Col. Roger Ducey; both provide a vision for getting DMT off the ground floor while dealing with limited resources. Finally, special thanks to Maj. Tony Gould, my advisor, whose expertise in modeling and simulation was much needed and appreciated. 


\begin{abstract}
The current military budget restrictions create a need to explore alternative ways of training aircrew members. The purpose of this paper is to examine the benefits of simulator integration in Air Mobility Command (AMC) as an alternative training method.

The initial discussion is the mandate by the Undersecretary of Defense for Acquisition and Technology to convert all DoD simulators to High Level Architecture (HLA). Converting simulators to HLA enables them to interact seamlessly, providing crews the benefit of Distributive Mission Training (DMT). After presenting the current AMC flying hour and simulator program, an explanation and analysis is provided. Next, a notional flying time savings is proposed followed by the obstacles and advantages to substituting simulator time for actual flying time. Finally, the research concludes that not funding HLA/DMT in the FY00 POM was a mistake. There are a few technological obstacles that need to be solved before DMT will be fully functional. However, was consideration given to budget lead times of 5 to 7 years? This must be weighed against Moore's Law which states that micro technology will double every 18 months at the same price. When the obstacles are solved, DMT promises to provide better, more efficient training at a significant cost reduction. Because DMT can provide better prepared crews for combat, the progress of DMT must be followed closely to determine if and when it becomes a viable training method.
\end{abstract}




\section{Chapter 1}

\section{Introduction}

The current military budget restrictions create a need to explore alternative ways of training aircrew members. The purpose of this paper is to examine the benefits of simulator integration in Air Mobility Command (AMC) as an alternative training method. Interactive simulators allow training to be more efficient and effective at a significant cost reduction. Perhaps the biggest benefit of this new simulator technology is mission rehearsal. The ability to practice real-world missions in an exact replicated environment will reduce the fog and friction of combat operations while better training the crewmembers. While there exist technological obstacles that need to be solved before simulator integration can become a reality, this program has support from very high ranking officials.

In a message on 14 Feb 1996, then Chief of Staff Gen. Ron Fogleman stated that he was convinced the modeling and simulation technology that existed would significantly change the manner in which the Air Force trains. He directed an investigation to determine the best manner to incorporate this technology into training and named the $\mathrm{AF} / \mathrm{XO}$ as lead agent. He wanted a look into how training assets could function in a synthetic battlespace, with "the full range of tactical assets available to the joint task

force commander"1. He also asked what the appropriate interaction between major 
weapon systems should be and requested a response that would meet the close out of the FY98 Program Object Memorandum (POM) cycle. This message resulted in several DoD agencies becoming involved with simulator upgrades.

The Undersecretary of Defense for Acquisition and Technology, Mr. Paul Kaminski, published a message in Sept of 1996 stating that High Level Architecture (HLA) was designated as the standard technical architecture for all simulations in DoD. His message established the DoD Executive Council for Modeling and Simulation (EXCIMS) giving them the responsibility to manage the evolution of HLA. The biggest impact of this message was the mandate that "Departments shall cease further development or modification of all simulations which have not achieved, or not in the process of achieving, HLA-compliance by the first day of FY 1999, and shall retire any noncompliant simulations by the first day of FY 2001."2 It went on to task the Defense Modeling and Simulation Office (DMSO) to monitor compliance with HLA and submit periodic progress reports. So what does this mean? In a nutshell, all of DoD must plan converting their simulators to be HLA compliant and have a conversion program started by 1 Jan 99 . If your simulators are not in the conversion process, they will be retired by 1 Jan 2001. Also, any new simulators purchased will have to be HLA compliant. However, there are some exceptions which can be waived. An example would AMC's C-141 simulator. With the last aircraft due to retire in 2006, it makes no sense to spend millions converting the simulator for only a few years of use.

So, what is HLA and why do we need it? Basically, "HLA has three components: a set of rules on how simulators interact with each other, a Runtime Infrastructure (RTI) which controls the distribution of data, and an Object Model Template (OMT) which tells 
the format of the data." ${ }^{3}$ By following the HLA rules of interaction, all DoD simulations will be able to exchange data effectively. This will allow a navy aircraft carrier simulator in Norfolk, VA to be able to interact with a flight of 4 F-16 simulators at Eglin AFB, FL which are being controlled by controllers from an AWACs simulator at Tinker AFB, OK - and this is all done in real time! Other benefits will be covered in Chapter 6, but as you can imagine, there is great potential to save money by flying realistic simulators instead of the aircraft. Reductions in operations tempo and TDY costs could occur by conducting exercises in the synthetic battlespace instead of deploying the wing, fleet, or brigade. The product of this simulator interaction is called Distributive Mission Training (DMT).

While this all sounds really good, there are some major stumbling blocks. The biggest being the incredible amount of money it will take to convert all the DoD simulators to HLA. Where is the money coming from? Like many of the recent mandates from Washington, this one doesn't come with any money, so each service and command is left to find the 100 s of millions of dollars in their already tight budgets to implement this program. Each service and command must decide if it is better to convert the existing simulators or is it better to buy new ones. Air Combat Command (ACC) decided to do the latter through the purchase of new simulators to implement their F-15 ACES program. Other roadblocks such as technology and pilot perceptions will be addressed in the chapter 5 .

Finally, this is a multi-faceted project, with unique problems for each service and for each command in each service. The fighter community is concerned with how to simulate G-forces and enemy threats. The army has a need for an exact representation of a small 
geographic location while the Air Force doesn't require much detail, but needs huge amounts of space for an operating environment. For example the Army may only need 5 square miles to conduct operations, but the Air Force would need 2,000. The technological trade-offs between scope and detail are driven by the missions each service performs and the result is a competition for a limited amount of space in a computer database. Although there are vast challenges to every service and command, this paper is limited to analyzing the benefits of simulator integration to Air Mobility Command (AMC). Can simulator technology really provide the realistic training for the aircrew and how can AMC pay for a large, but mandatory program? This paper will analyze AMC's flying time program in order understand where simulator training could be substituted and to establish a background in aircraft operating costs. Next, the current AMC simulator program will be analyzed. After the flying and simulator programs are discussed, a potential flying hour savings will be proposed. Next, the obstacles and advantages to simulator integration will be examined. Finally, an overall examination of the data and a conclusion will be drawn.

\section{Notes}

${ }^{1}$ Message, 141957Z Feb 96, CSAF to SECDEF, AFMC, AETC, AMC, ACC, AFSPC, NGB, HQ USAF, AFSOC, AFOTEC, AIA, ESC, 14 Feb 1996.

${ }^{2}$ Mr Paul Kaminski, Under Secretary for Defense for Acquisition and Technology, memorandum for Secretaries of the military departments, CJCS and Under Secretaries of Defense, 10 Sept 1996.

${ }^{3}$ ASC Wright Patterson AFB OH. Simulator Networking Requirements Analysis, 1998, n.p.; online Internet, 17 Nov 1998, available from http://140.175.188.129/cfdocs/orangebook/nra7777a.htm. 


\section{Chapter 2}

\section{AMC's Flying Hour Program}

A basic knowledge of AMC's flying hour program is required to examine where efficiencies may or may not be gained. There are 4 major categories of flying time, each with a specific purpose. The first is the Transportation Working Capitol Fund (TWCF), the second Training, Test, Ferry (TTF), third Contingencies and fourth Exercises. AMC/DOT has a highly dedicated section that tracks the current year execution of flying time by aircraft type and by category. This is done because of the different funding levels for each category. There is another section in AMC/DOT that is dedicated to the programming of flying time for input into the POM cycle. This chapter will explain the different categories and the operating costs of the major weapon systems in AMC, namely C-17, C-141, C-5, KC-10 and KC-135. NOTE: The C-130 was transferred back to AMC from ACC in 1997. The flying time program is still in the process of being transferred.

First, the Transportation Working Capitol Fund (TWCF) is AMC's business fund.

This is the flying time that is executed in support of its customers. When the $10^{\text {th }}$ Mountain Division needs to deploy, the flying time is flown out of the TWCF. The set up is fairly simple in that all major commands and services that will need transportation support from AMC program, in their POM, the funding needed to "buy" airlift from 
AMC. During the execution year, those commands will contract AMC to move their people and equipment. AMC will then charge that unit for reimbursement of the flying time flown to support them. The rate charged is dependent on the kind of support given. There are different levels of support given depending on whether the mission was contracted as a Special Assignment Airlift Mission (SAAM), a Channel mission, or a Joint Airborne/Airtransportability Training (JA/ATT) mission. The flying time costs for each aircraft are determined by AMC/FMBT or by the Air Force Cost Analysis Improvement Group (AFCAIG), and based on the aircraft type. This enables everyone to accurately program funding in the POM. Once the rate is set for that POM year, a standard inflationary rate provided by Program Budget Decisions (PBD) is applied to determine the rates for the subsequent years. These rates will vary depending on the type of TWCF support you desire. The SAAM rates are the highest, but when you contract for a SAAM, that aircraft is usually dedicated to you until the contract is complete. Your funding, mission requirements, priority and aircraft availability will determine what kind of TWCF support you contract.

The second category of flying time, sometimes referred to as continuation flying time, has three aspects Training, Test and Ferry (TTF). Training time is the time flying squadrons use to maintain or upgrade the aircrews flying proficiency. There are numerous tables that determine training requirements that each crewmember needs to accomplish in a six month period. Some events are currency based, requiring their accomplishment periodically. An example would be a pilot required to complete a landing every 45 days or less. Other requirements are numerical and based only on accomplishment of a minimum number items in that six month training period. An 
example would be five night fighter contacts for a boom operator to maintain proficiency. Each crewmember is required to complete a minimum amount of training per period to maintain his/her full mission qualified status, i.e. warfighting capability. Each event requires a certain amount of flying time to accomplish those tasks. Add up the flying time per crewmember and you can determine the required training flying time. Also, included in this flying time are the annual checkrides for the crewmembers. Additionally, periodic upgrade training is done for normal job progression. This includes the training required for co-pilots to upgrade to become first pilots and for first pilots to aircraft commander. It also includes the upgrades to instructor and/or evaluator status.

The second aspect, test time, is flying time reserved to fly an aircraft for the purpose of testing equipment that has been replaced and needs to be checked in the air. The third aspect of TTF time, ferry time, is the flying time needed to fly aircraft to and from Depot maintenance facilities for major repairs and inspections.

Not all continuation flying is done in flight. Some continuation training has been moved into the simulator because of their increased capabilities. The simulators that meet specific criteria, FAA level C+ discussed in the next chapter, enable enough realistic training for crewmembers to credit those training events in the simulator. An example would be that two of the four pilot proficiency flights can be logged in the simulator. As simulator technology improves, more and more training can be executed there. However, the technology that exist in the current AMC simulators limits the amount of training that can be moved, including any training that requires the interaction between two or more aircraft. For example, technological limitations don't allow for air refueling training or formation flying to be conducted in AMC simulators. One of the 
promises of DMT is to overcome that obstacle and move all training into the simulator. By integrating simulators, safer more efficient training can be accomplished at less expense. The cost difference between operating a simulator at $\$ 500$ an hour and the cost of flying the aircraft is a major advantage to DMT. Table 1 details the programmed flying time costs in FY00 for each of the major weapon systems in AMC. This price is set to fully recover all costs associated with the aircraft. As indicated, there is a tremendous price differential between a simulator and the aircraft.

\begin{tabular}{|lccccc|}
\hline FY00-Estimates & C-5 & C-17 & C-141 & KC-135 & KC-10 \\
$\begin{array}{l}\text { Cost per Training } \\
\text { flying hour }\end{array}$ & $\$ 14,400$ & $\$ 9,000$ & $\$ 7,400$ & $\$ 2,175$ & $\$ 9,000$ \\
\hline
\end{tabular}

Table 1. Flying hour costs for Continuation Training

The final 2 categories that go into the overall flying time program are JCS supported exercises and contingencies. Until recently, contingency flying time could not be programmed, but was flown and may or may not be reimbursed. Given that Northern/Southern Watch and Bosnia have no termination in sight, this was recently changed to allow for more accurate programming while retaining acceptable training levels. These two categories are a smaller portion of the overall flying hour program, but they are still required to be programmed.

Table 2 below shows an approximate picture of the overall fly time program for AMC. Because the POM is a dynamic and fluid process, changing sometimes daily, the numbers in Table 2 reflects what is in the program as of November 1998 and are intended to give you an idea of the relative size and cost of the program. 


\begin{tabular}{|lrrrrr|}
\hline CATEGORY/PEC & $\mathrm{C}-5$ & $\mathrm{C}-17$ & $\mathrm{C}-141$ & $\mathrm{KC}-135$ & $\mathrm{KC}-10$ \\
FERRY & 234 & 176 & 256 & 0 & 0 \\
ACTIVE TNG & 4,922 & 8,845 & 9,247 & 55,789 & 27,261 \\
JA/ATT & 571 & 3,610 & 2,658 & 0 & 0 \\
ASOC TNG & 3,230 & 4,408 & 4,756 & 0 & 0 \\
JCS EXERCISES & 4,627 & 5,958 & 4,698 & 0 & 0 \\
SAAM & 11,569 & 21,542 & 14,457 & 0 & 811 \\
CHANNEL & 12,725 & 18,334 & 16,987 & 2,936 & 4,000 \\
CONTINGENCY & 6,660 & 0 & 0 & 7,720 & 4,956 \\
\hline Total & 44,538 & 62,873 & 53,059 & 66,445 & 37,028 \\
\hline
\end{tabular}

Table 2. FY00 Programmed Flying Hours

As shown above, the $\mathrm{C}-5, \mathrm{C}-17$, and $\mathrm{C}-141$ have a majority of their time in TWCF, while the tankers show a majority in training. The difference is partly due to the training events that have been moved to the simulator for the C-5, C-17 and C-141. In FY00 the tanker simulators are still in the upgraded process. However, there still exists a substantial amount of flying time dedicated to training for all five aircraft, as shown on line 2 (active training) of Table 2. This is the flying time that could be reduced by DMT implementation. Next is an analysis of the simulator program. 


\section{Chapter 3}

\section{AMC's Simulator Program}

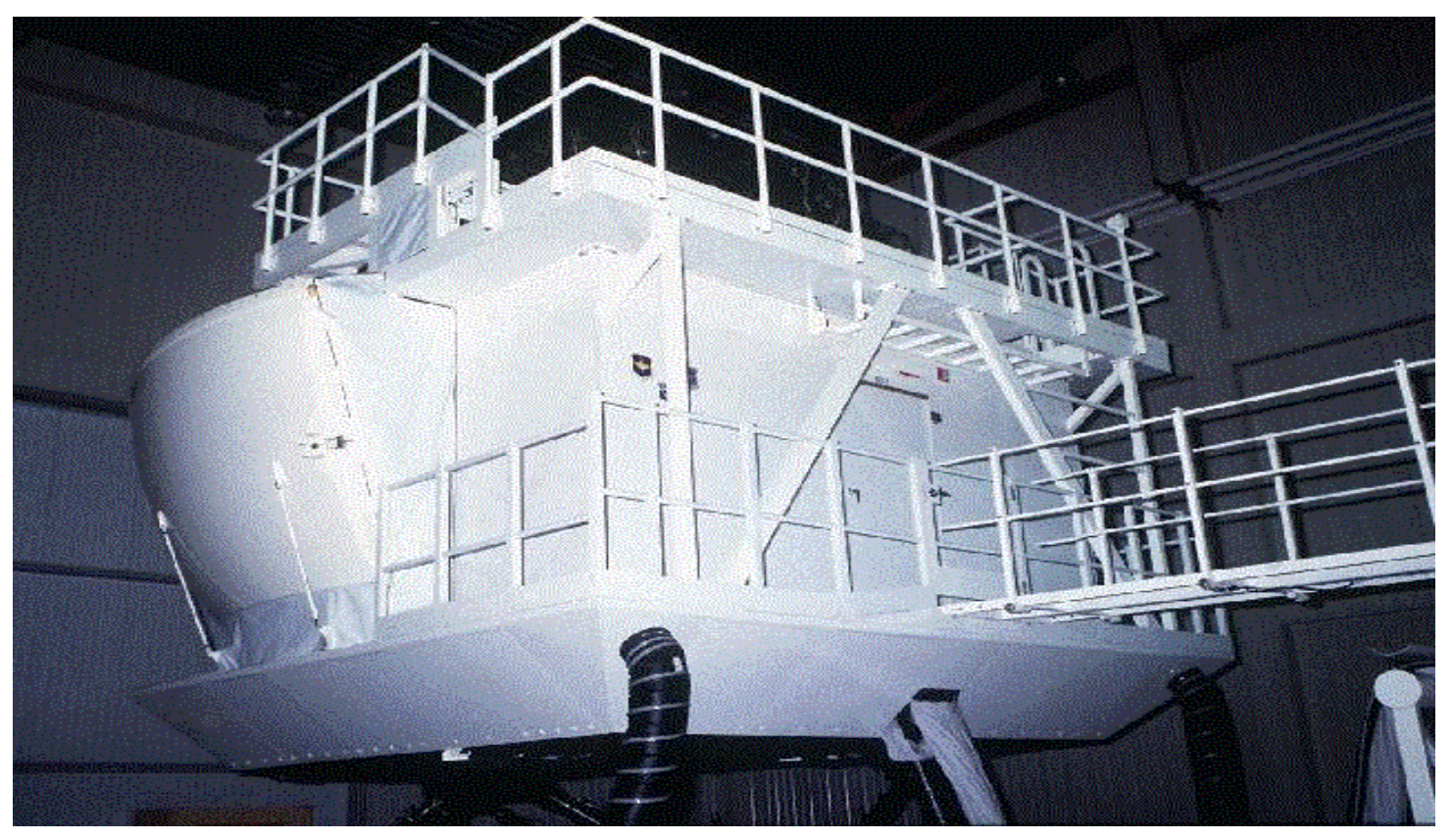

Figure 1

With the AMC flying hour program as background, let's examine the simulator program, by starting with a definition. The Defense Modeling and Simulation Office (DMSO) defines a simulator by; "For training, a device which duplicates the essential features of a task situation and provides for direct human operation." ${ }^{\text {AMC currently }}$ operates and manages 88 simulators with a wide range of capabilities. Some are on the cutting edge of technology, while others, such as a Cockpit Part Task Trainer (CPT) may 
only be a tabletop trainer. For our purpose, we will focus on those simulators having the greatest potential for savings by incorporating DMT, specifically the aircraft simulators.

AMC is heavily dependent on simulators. In the early 90 s, with the prospect of flying time cuts, AMC decided to upgrade their simulators and take advantage of the increased capabilities available. To ensure training was kept at an acceptable level with the flying time cuts, they decided to emulate what the airline industry had done. In the mid-80s the airline industry had concluded that simulators had enough capabilities to enable them to conduct a majority of their training in a simulator. So, in 1992 AMC started a massive investment to upgrade their simulator's performance.

The basic parts of an aircraft simulator consist of the cockpit, a screen, a sound system, the motion platform, a central computer, a database, an image generator, and projectors. AMC decided to use the Federal Aviation Administration (FAA) industry standards to determine the acceptable performance criteria. The FAA has four levels of performance for simulators, levels $\mathrm{A}, \mathrm{B}, \mathrm{C}$, and $\mathrm{D}$, with $\mathrm{D}$ being the most capable and also the most expensive. A mid-80s study by the airline industry showed that level $\mathrm{C}$ was the minimum level acceptable to substitute simulator training for flying training. However, AMC realized that there are differences in the training of airline pilots and military pilots. First, airline pilots are generally more experienced than their military counterparts. Also, the military missions are generally, more complicated than the airline flights. AMC decided that while FAA level $\mathrm{C}$ was an acceptable level for most equipment, the visual system would have to meet FAA level D specifications. This combination of compliance levels is referred to as level $\mathrm{C}+$, standing for FAA level $\mathrm{C}$, plus enhanced visual effects, which meet the level D specifications. 
Level C requires the simulator cockpits to have the same switches and controls found in the aircraft. In other words, the cockpit has to be a full-scale replica of the aircraft. Simulator systems have to respond accurately and in the same manner as the aircraft. Other specifications include 6 degrees freedom of motion and aerodynamic and ground effects that have the same characteristics as the aircraft. Finally, simulated control surfaces must react like the real aircraft and respond within 150 milliseconds. This lets the simulator feel and sound like the real thing! The added visual requirements to level D include a wider angle of view, 225 degrees versus the 75 degrees called for in level C. Also added were daytime lighting, a cross-cockpit field of view and improved texture. "Texture is the visual system equivalent of "wall paper." It increases the scene content without loading the system down excessively. It improves realism and provides the eyes with additional visual cues to help with altitude and speed control."2 The cross-cockpit field of view enables one pilot to see out the window of the other and visa versa.

To pay for these upgrades, AMC and the Air Staff negotiated an agreement. The Air Staff would fund these upgrades up front, in exchange for flying time cuts in future years, after the simulators became operational. This was a win-win situation for both parties. AMC was able to source their upgrade program, and the Air Staff was able to provide savings in the overall budget. AMC's major concern was that the performance of these new simulators would not meet their training requirements. While this simulator technology had demonstrated that it met airline specifications, would it provide meaningful training for the military? To guard against failure, AMC initially moved only a small percentage of the training events into the simulator until acceptable performance was demonstrated. Even after successful demonstrated, AMC only moved 50\% of the 
continuation training into the simulator. Yet because flying time costs are so much more expensive than a simulator (typical simulators can operate around $\$ 500$ an hour versus a C-5 flying hour cost of $\$ 14,400)$ the upgrades more than paid for themselves in a few years.

Now that we have some background on the AMC simulator program and how it got started, let's look at how the implementation of DMT effects the overall program. Specifically, is more equipment needed, and how is AMC going to pay for it?

The first question AMC faced after DMT was mandated, was whether to start from scratch, with brand new simulators, or should the upgrade program continue, and roll DMT into the process. AMC choose to go with the program they already had in place. At approximately the same time, ACC who didn't have a simulator upgrade program in progress, decided to buy all brand new simulators and paid for them the same way AMC had in the past, with future year flying hours. The cost of a new simulator for AMC, fully DMT compliant and FAA $\mathrm{C}+$ is between $\$ 15$ and $\$ 20$ million. To convert an already FAA level $\mathrm{C}+$ simulator costs between $\$ 1.5-\$ 2 \mathrm{M}$ per device. For the 75 simulators that would be converted, the total program cost is about $\$ 175 \mathrm{M}$. This includes the testing required, the improvements in data base storage and other expenses.

This large bill combined with other mandates led AMC/CC to decide not to fund DMT in the 00 POM. This raises the question, why isn't DMT paid for in the same manner that the simulator upgrade program was paid for? As previously mentioned, AMC has not eliminated their training hour program. In fact, even with the simulator upgrades, crewmembers still maintain proficiency in $50 \%$ of their regular requirements and $100 \%$ of their air refueling, airdrop and formation flying requirements in the aircraft. 
These are the very training events that could be moved into the simulator if DMT was fully implemented. There is tremendous amount of savings to be made by moving those training events into the simulator (see training time in Table 2). Does that mean all flying will be done in the simulator? The answer is probably not. AMC still needs to fly their TWCF program to support their customers. The contingencies and the channel missions will still need to be supported and tanker crews will still need to air refuel their customers.

How is simulator capacity effected? According to Lt. Col. Cost, AMC/DOTA, the simulators are designed with a $98 \%$ reliability rate with a usage of 20 hours a day, 355 days a year for total of 6,958 hours available per year. But, the statement of work (SOW) usually calls for a maximum of 16 hours a day for only 251 days. This results in 4,016 hours available under contract but the typical usage rate is only 3,500 hours. This leaves an additional 500 hours (2 hours a day) under the current SOW for additional training. Additional DMT requirements would exceed those 2 hours a day. Rewriting and renegotiating the SOW along with additional simulators would be required to meet the additional requirements. Now that the simulator and flying time programs have been examined, let's examine the potential flying time savings that could occur if DMT was fully implemented and worked as promised.

\section{Notes}

1 DoD Directive 5000.59, DoD Modeling and Simulation (M\&S) Management, January 4, 1994, available from http://www.dmso.mil

2 ASC Wright Patterson AFB OH. Simulator Networking Requirements Analysis, 1998,n.p.; online Internet, 17 Nov 1998, available from http://140.175.188.129/cfdocs/orangebook/vue.htm 


\section{Chapter 4}

\section{Potential Flying Hour Savings}

This chapter will analyze the potential cost savings to AMC if they fully implemented DMT. The intent of this chapter is not to give a perfect solution to the problem, but to give the readers an approximate understanding for the potential monetary savings that DMT provides. First, let's quantify the flying time numbers used.

Today, there exist several obstacles to full DMT implementation. Those obstacles will be covered in the next chapter. Also realize that the flying time numbers that are used are only a good estimate of the program at the time of the paper's construction. Estimates are used because of the dynamic changes in training requirements during the Planning, Programming, and Budgeting System (PPBS), effecting the flying time allocation. Along with training requirement changes, funding of the flying time is also changed throughout the PPBS process. Thus, the flying time numbers in the tables below reflect the best estimates available.

Tables 3 through 6 show the training time programmed for 4 of the AMC aircraft. The C-141 program is not shown, due to its scheduled retirement and the C-130 flying time program, as stated earlier, has not transferred from ACC. Also, the data for the KC10, KC-135, and C-5 is for FY00 only, because the data for FY01 - FY05 is the same. 


\begin{tabular}{|l|r|}
\hline C-5 Training Hours & FY00 \\
Local Proficiency & 1917 \\
FP Upgrade & 387 \\
IN-UNIT Requalification & 61 \\
Air Drop-Initial Upgrades & 26 \\
Continuation Training & 142 \\
SOLL II - CONTINUATION & 479 \\
ORI & 209 \\
Air Refueling & 1006 \\
FAR & 31 \\
\hline Total & 4,258 \\
\hline
\end{tabular}

Based on 116 AC, 58 FP, 58 CP, 44 staff and a PAA of 64

Table 3. C-5 Continuation Training Flying Time

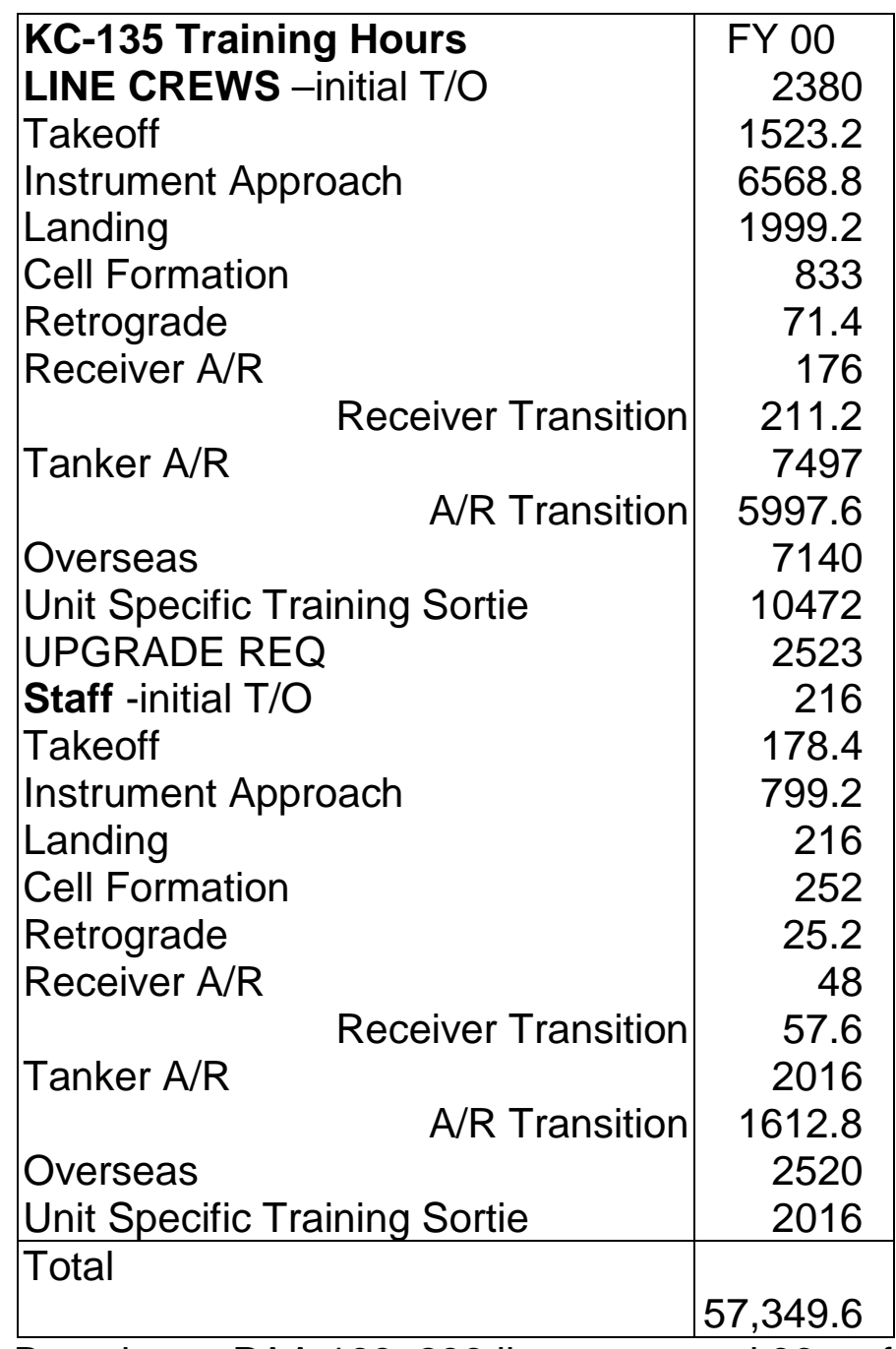

Based on a PAA 168, 238 line crews and 96 staff pilots

Table 4. KC-135 Continuation Training Flying Time 


\begin{tabular}{|c|c|}
\hline KC-10 Training Hours & FY00 \\
\hline Line - Initial Takeoff & 1080 \\
\hline Takeoff & 691.2 \\
\hline Instrument Approach & 2980.8 \\
\hline Landing & 907.2 \\
\hline Receiver A/R & 1188 \\
\hline $\begin{array}{l}\text { Receiver Transition } \\
\text { Tanker A/R }\end{array}$ & $\begin{array}{r}1425.6 \\
1782\end{array}$ \\
\hline A/R Transition & 1425.6 \\
\hline Cell Formation & 756 \\
\hline Overseas & $\begin{array}{l}6480 \\
5184\end{array}$ \\
\hline $\begin{array}{l}\text { Unit Specific I raınıng sortie } \\
\text { Staff - Initial Takeoff }\end{array}$ & $\begin{array}{r}5184 \\
70\end{array}$ \\
\hline Takeoff & 58.8 \\
\hline Instrument Approach & 266.4 \\
\hline Landing & 73.2 \\
\hline Receiver A/R & 208 \\
\hline Receiver Transition & 249.6 \\
\hline Tanker A/R & 312 \\
\hline A/R Transition & 249.6 \\
\hline Cell Formation & 156 \\
\hline Overseas & 780 \\
\hline Unit Specific Training sortie & 1248 \\
\hline Total & $27,572.0$ \\
\hline
\end{tabular}

Based on 54 PAA, 108 crews and 35 staff crews

Table 5. KC-10 Continuation Training Flying Time

\begin{tabular}{|lrrrrrr|}
\hline C-17 Training Hours & FY 00 & FY 01 & FY 02 & FY 03 & FY 04 & FY 05 \\
Average PAA & 44 & 55 & 68 & 82 & 94 & 96 \\
Average AC & 132 & 165 & 204 & 246 & 282 & 288 \\
Average CP & 66 & 83 & 102 & 123 & 141 & 144 \\
\hline LOCAL TRAINING & 2782 & 3484 & 4304 & 5183 & 5941 & 6071 \\
IN-UNIT REQUAL & 76 & 93 & 115 & 137 & 159 & 164 \\
AIRDROP & 1373 & 1717 & 2115 & 2550 & 2935 & 2987 \\
SOLL II & 257 & 514 & 767 & 744 & 744 & 744 \\
RED FLAG & 244 & 292 & 365 & 462 & 511 & 535 \\
ORI & 637 & 797 & 985 & 1188 & 1362 & 1391 \\
\hline Total & 5,369 & 6,897 & 8,651 & 10,264 & 11,652 & 11,892 \\
\hline \multicolumn{5}{c}{ Based on average PAA and pilots for that year } \\
\hline
\end{tabular}

Table 6. C-17 Continuation Training Flying Time 
The $\mathrm{C}-17$ is still a growing major weapon system and the increase in flying hours and Primary Aircraft Assigned (PAA) are shown in Table 6 along with the pilot growth.

As the tables show, the continuation training time represents a large amount of the flying hours and dollars. The $57,350 \mathrm{KC}-135$ hours in Table 4 is $86 \%$ of the total flying hour program. The $27,572 \mathrm{KC}-10$ hours is $76 \%$ of the total program while the 4,258 C-5 hours and the 5,369 C-17 hours are only $10 \%$ of their overall program. To get an idea of the dollar amount, take the KC-135 hours and multiply it by the dollar amount given in Table $1(57,350 \mathrm{hrs} \times \$ 2,175=\$ 124.7 \mathrm{M})$. The $\mathrm{C}-5$ adds $\$ 61.3 \mathrm{M}$, the $\mathrm{C}-17$ equals $\$ 48.3 \mathrm{M}$ in FY00 and the KC-10 adds $\$ 248 \mathrm{M}$. As the dollar figures and the percentages above indicate, the largest training time exist in the two tanker fleets. They also have the lowest amount of training time credited in the simulator. Their simulators are still in the process of being upgrading, versus the $\mathrm{C}-5$ and $\mathrm{C}-17$ simulators which are complete. It must be noted that the $\mathrm{C}-5, \mathrm{C}-17$ and $\mathrm{C}-141$ programs haven't reduced their training requirements, just the flying hours, because the events are still accomplished in the simulator. This is an important point, because training isn't being reduced. AMC already trains to the minimum necessary to maintain crewmember capabilities. However, as stated earlier, flying a $\$ 500$ an hour simulator is more economically feasible than a $\$ 14,400$ C-5 aircraft. As the upgrades to the tanker simulator progress, more events will be moved there. A percentage of takeoffs, instrument approaches, landings, and unit specific sorties will be moved, as they were in the C-5 program. Now let's examine the impact and events that could be moved from aircraft into the simulator with DMT implementation. 
To get an estimate on the dollar impact of moving events to the simulator, let's first examine how the flying time is determined. Table 4 shows that for FY00 the KC-135 cell formation is programmed for 833 hours. This number is determined by taking the number of pilots (238) multiplying the flying time it requires to accomplish the event (1 hr) and then multiply the number of events required per pilots per year (7). Finally, you multiply any other conditions that might exist. In this case, only $50 \%$ of the time is allocated, because 2 pilots get credit for that event at the same time (the aircraft commander and the co-pilot). So 833 hours is determined by 238 crews $x 1 \mathrm{hr} \times 7$ events x 50\% credit. Now that a background has been covered on how the flying timetables are set-up, let's take a hypothetical look at what events can realistically be accomplished in a DMT simulator.

Table 7 on the following page details an estimate of the flying time that could be reduced by moving training events into the simulator. The $\mathrm{C}-5$ program is displayed at the top. A 50\% cut in the air refueling, airdrop and formation air refueling will reduce the training time by 590 hours. When you multiply the 590 hours by the cost per flying hour of $\$ 14,400$ found in Table 1 a savings of $\$ 8.488$ million is realized.

Next, the KC-135 flying time shows a cut by half in cell formation, receiver air refueling and transition time along with a one-third cut in tanker air refueling, transition and unit specific training sorties. This produces a reduction of 10,659 hours. Multiply this by $\$ 2,175$ pre flying hour and a total KC-135 flying time savings is $\$ 23.184$ million.

The KC-10 programs shows a one-third reduction in tanker and receiver air refueling and transition, along with a 50\% reduction in cell formation and unit specific training sorties. This produces a 5,952 hour flying time reduction and when multiplied by $\$ 9,000$ 


\begin{tabular}{|c|c|c|c|c|c|}
\hline C-5 & From Table 3 & cut & Reduced Hrs & & \\
\hline Airdrop & 142 & $1 / 2$ & 71 & & \\
\hline Air Refueling & 1006 & $1 / 2$ & 503 & & \\
\hline FAR & 31 & $1 / 2$ & 16 & \$ per hr. & Savings \\
\hline Total & & & 590 & 14,400 & $\$ 8,488,800$ \\
\hline KC-135 & From Table 4 & cut & Reduced Hrs & \multirow{12}{*}{ Staff } & \multirow[b]{13}{*}{ Savings } \\
\hline Cell Formation & 833 & $1 / 2$ & 417 & & \\
\hline Receiver A/R & 176 & $1 / 2$ & 88 & & \\
\hline Transition & 211.2 & $1 / 2$ & 106 & & \\
\hline Tanker A/R & 7497 & $1 / 3$ & 2499 & & \\
\hline Transition & 5997.6 & $1 / 3$ & 1999 & & \\
\hline Unit Specific & 10472 & $1 / 3$ & 3491 & & \\
\hline Cell Formation & 252 & $1 / 2$ & 126 & & \\
\hline Receiver A/R & 48 & $1 / 2$ & 24 & & \\
\hline Transition & 57.6 & $1 / 2$ & 29 & & \\
\hline Tanker A/R & 2016 & $1 / 3$ & 672 & & \\
\hline Transition & 1612.8 & $1 / 3$ & 538 & & \\
\hline Unit Specific & 2016 & $1 / 3$ & 672 & $\$$ per hr. & \\
\hline Total & & & 10,659 & 2,175 & $\$ 23,184,123$ \\
\hline KC-10 & From Table 5 & cut & Reduced Hrs & \multirow{12}{*}{ Staff } & \multirow[b]{13}{*}{ Savings } \\
\hline Receiver A/R & 1188 & $1 / 3$ & 396 & & \\
\hline Transition & 1425.6 & $1 / 3$ & 475 & & \\
\hline Tanker A/R & 1782 & $1 / 3$ & 594 & & \\
\hline Transition & 1425.6 & $1 / 3$ & 475 & & \\
\hline Cell Formation & 756 & $1 / 2$ & 378 & & \\
\hline Unit Specific & 5184 & $1 / 2$ & 2592 & & \\
\hline Receiver A/R & 208 & $1 / 3$ & 69 & & \\
\hline Transition & 249.6 & $1 / 3$ & 83 & & \\
\hline Tanker A/R & 312 & $1 / 3$ & 104 & & \\
\hline Transition & 249.6 & $1 / 3$ & 83 & & \\
\hline Cell Formation & 156 & $1 / 2$ & 78 & & \\
\hline Unit Specific & 1248 & $1 / 2$ & 624 & $\$$ per hr. & \\
\hline Total & & & 5,952 & $\$ 9,000$ & $\$ 53,569,200$ \\
\hline $\mathrm{C}-17$ & From Table 6 & cut & Reduced Hrs & \multirow[b]{4}{*}{$\$$ per hr. } & \multirow[b]{4}{*}{ Savings } \\
\hline Airdrop & 1373 & $1 / 3$ & 458 & & \\
\hline Red Flag & 244 & 1 & 244 & & \\
\hline ORI & 637 & $1 / 2$ & 319 & & \\
\hline Total & & & 1,020 & 9,000 & $\$ 9,181,500$ \\
\hline Grand Total & & & 18,221 & & $\begin{array}{c}\text { otal Savings } \\
\$ 94,423,623\end{array}$ \\
\hline
\end{tabular}

Table 7. Notional Flying Time Reductions

per hour equals $\$ 53.569$ million in savings.

At the bottom of Table 7, the C-17 program reduces a third of the airdrop hours, all of the Red Flag hours and half of the ORI hours for a total of 1,020 hours. Multiply the 1,020 hours by $\$ 9,000$ per hour and the total $\mathrm{C}-17$ savings is $\$ 9.181$ million. The 
total savings in flying time for the four programs equal $\$ 94.4$ million in ONE year. Are these realistic numbers? Even if the reductions were figured at $25 \%$ instead of percentages used above, total savings to the flying hour program exceeds $\$ 40$ million a year. The total HLA conversion will cost AMC \$175M. Even at the $25 \%$ cut rate, the program would pay for itself in less than 5 years. So why did AMC decide not to fund this project and why aren't more military units embracing this technology? One big problem is that there is no proof that flying AMC simulators together will produce effective training. There are several other obstacles that will be covered in the next chapter. But, if solutions are found to these problems, the cost savings potential is tremendous. Other factors to consider are the savings in aircraft parts. As the utilization of the aircraft is reduced, mission reliability rates increase, saving on replacement parts and increased time between major repairs. Eventually, joint exercises will occur in the synthetic battlespace, thus reducing TDY costs and the wear and tear on equipment. Finally, readiness is increased through a more realistic environment that doesn't impose peacetime restrictions. While this all sounds good, there are some major hurdles that need to be overcome before we get to the point where we are conducting exercises in cyberspace. 


\section{Chapter 5}

\section{Obstacles to Simulator Integration}

There are three main obstacles to fully implementing DMT. The first has already been discussed, the initial costs of converting the simulators. The other two problem areas exist in technological support and pilot perceptions. Until all three of the obstacles are resolved, AMC will not realize the full benefits of DMT. Since the funding issue has been covered in Chapter 4, let's analyze the technological and the perception problems.

While the DMT program has many benefits, today it is not a supportable program from a technological point of view. The first obstacle is a phenomenon called latency. DMSO defines simulator latency as "The time required for a device to begin physical output of a desired piece of data once processing is complete." ${ }^{1}$ In simpler terms, latency means the time for a computer to take a data input and make something happen. For example the pilot turns the yoke, and the computer turns that data into an output, such as the picture outside the cockpit turning as the pilot turns that yoke. In the modern simulator, this latency is so quick a pilot can't perceive it. However, when two simulators are interacting together latency becomes a problem. To illustrate, when two aircraft simulators are flying in formation and one simulator initiates a turn, it takes time for that input to go from the turning aircraft into the computer, process, then go out to both display screens. If both simulators are located in the same building, the latency is 
barely perceivable. However, the goal of DMT is to integrate simulators, not only when co-located but also with those separated by thousands of miles. The time it takes for a piece of data to go from a simulator at Charleston $\mathrm{AFB}, \mathrm{NC}$ into the computer, then out through the Run Time Infrastructure (RTI), into a computer at Travis AFB, CA then projected on the simulator screen, is a lot longer than the same piece of data traveling across a building. Latency is also a problem for simulated actions between two simulators that occur in very close proximity in cyberspace. During air refueling, the latency can be so bad between the simulators, even when co-located, that the receiver pilot can't accurately locate the tanker aircraft's boom. A possible solution to the latency problem is what an AT\&T representative calls a "faster-than-real time" RTI. The idea that the data can travel faster than the real time it takes to see the action, is years away from being developed and waiting for a technology breakthrough, but is being explored.

Another obstacle that needs to be overcome is the physical limitation on the amount of information that can be transferred at any one time. If you have ever logged onto the internet and waited for your favorite web page to open, you've experienced the limitation of inadequate bandwidth. There exists today a physical limit on the amount of data a phone line can hold and transfer at any one time. The massive amounts of data that will need to be exchanged in a full-scale battlefield exercise are beyond the physical limitations of any telephone or data lines in use today. There are a couple of efforts being developed to be able to handle increased capacity. The good news is that the internet would benefit from this new technology, so there is a commercial application and interest to improve the data transfer rate. One of many possibilities is the use of satellite technology. Direct TV uses this technology today, and transfers data at 400Kbps. This is 
28 times faster than the average modem and 3 times faster than the fastest ISDN (Integrated Services Digital Network) connection available today. One major drawback to using the Direct TV satellite dish is that as of today, they receive signals but they cannot transmit. Therefore, you still have the problem of physical line limitations when you want to send data, because you are still relying on a telephone line.

A third technical obstacle that needs to be addressed is the issue of network security. As information distribution becomes more and more relevant, security of our information systems becomes very important. Tactics, techniques, force structure, standard operating procedures, intelligence sources and command and control are but a few of the areas where our enemies would like to gain information. If a joint exercise were conducted through simulators and simulations, who would control the access? How would monitoring of the access work? Who would protect the exercise from intrusion? Would everyone have equal access or would there be different levels of security access? These are all very important questions to address if you are going to conduct full-scale missions on an internet. Even non-classified operations such as air refueling are easier to monitor on the internet, versus monitoring in-flight. A sophisticated monitoring system would need to be developed that could restrict access and detect intruders. Until the security issues are resolved, there is too much risk to national security to conduct operations on a non-secure system.

Finally, DMT will require development of new and better simulators. One example would include a Boom Operator Simulator (BOS). This too would have to be an exact replica of the boom operator pod and be able to interact independently, or in correlation with the pilot simulator. This brand new simulator will need to be developed from 
scratch, which means it will be very expensive. It's purpose would be to provide the air refueling operations and coordination needed during in-flight air refueling, while training the boom operators. Every service will have to analyze their needs and may have to develop new simulators or upgraded the existing simulators to meet their training requirements. But even if this all does work and the technological problems are solved, will the user believe that a simulator actually performs like the real thing? This takes us to our next problem, perception.

It just may be human nature to not trust anything new. How many of your grandparents don't trust the stock market? Do your parents trust computers? While living the same day to day maybe desirable in everyday civilian life, the U.S. military can't afford that luxury if we are going to keep our technological superiority. New and inventive ways to conduct our business are required. This means "thinking outside the box" on how best to train our crewmembers. However, this isn't as easy as it sounds. Because of the technological problems mentioned above, and because of their own experience flying simulators in the past, many pilots, including the senior pilots making the budget decisions, do not believe that a simulator can accomplish everything that DMT promises. The problem with previous simulators is that they don't act or feel exactly like the aircraft. Because earlier simulators were technologically limited, pilots had to perform differently in the simulator to overcome those limitations. This is referred to as negative training, which means the pilots are learning to fly the simulator, not the aircraft. Also, until recently, the visual systems for the military simulators have not been very good. Two of the problems included a limited quality of texture and the second being inadequate visual acuity. This caused the images outside the cockpit to look out of focus 
and fuzzy. The pilots couldn't acquire the accurate hands-eye coordination required to fly aircraft. Add in the fact that some major weapon systems are just now getting motion on their simulators. The KC-135 for example has never had motion. How can a senior pilot who has never flown a simulator with motion or seen a FAA level D visual system be convinced that a simulator is as good as the aircraft? The answer is through education and a strict certification system. AMC already has a certification process established. The challenge is to create a set of criteria that details the performance of the simulator to a specification that is acceptable to the pilots, both in the field and on the staff.

In conclusion, there are many obstacles to DMT. Some technological breakthrough's are required to support the DMT program. However, even if the technology limitations are solved, the biggest obstacle may be the perceptions of the pilots who are also the AF decision-makers. If they truly believe that they can't get valuable training from simulators, then the DMT program will never get started. Conversely, if these obstacles can be overcome and the simulator performance meets pilot expectations, there are several advantages that can be realized from a full DMT program. These advantages will be discussed next.

\section{Notes}

${ }^{1}$ DoD Directive 5000.59, DoD Modeling and Simulation (M\&S) Management, January 4, 1994, available from http://www.dmso.mil 


\section{Chapter 6}

\section{Advantages to Simulator Integration}

The use of simulator integration to provide Distributive Mission Training (DMT) for crewmembers has numerous advantages. Using simulators is less expensive, more efficient, safer, more challenging. By using the aircraft less for training you increase the mission capability rate of the aircraft. While the monetary savings potential was covered in Chapter 4, this chapter will address the other benefits of DMT.

DMT should be important to AMC for the main reason that it will train the crews better than flying in the aircraft. Primarily this is because none of the safety restrictions that are imposed in flight need to be imposed in the simulator. This lets the crews actually practice the skills required for wartime fighting, instead of having to adhere to safety restrictions placed on them in peacetime. By incorporating air-to-air and groundto-air threats during a mission, crews can actually practice the maneuvers needed during combat to avoid those threats. This will give the crewmembers a realistic experience. The simulator system will also give the crew immediate feedback on their performance, both good and bad. By using a full DMT simulator, crews will be able to practice more demanding missions, without experiencing unacceptable risk. More demanding emergency procedures could also be accomplished, especially those requiring more than one aircraft, such as emergency air refueling. 
Training is more efficient in an integrated simulator. Typically during a mission there is time that is not being fully utilized. An example is the time it takes an aircraft to go from takeoff and fly to his air refueling track. The simulator is more efficient because it has the capability to reset to any geographic point desired. Flexibility is also inherent, since you may or may not choose to fly that drone time. Multiple approaches and landings can be accomplished in the simulator faster and more efficient because you don't have to worry about sequencing with other aircraft. But, again, the flexibility of the simulator allows you to put traffic in your profile if you choose. This would be important for a new copilot who is trying to learn how to pace himself in the traffic pattern.

Another advantage to increased usage of the simulator is that the decrease in flying time would increase the mission capable rate of the aircraft by reducing its utilization rate. If the aircraft aren't flown as much, major repairs are stretched out over a longer period of time and the demands on parts and repairs would decrease thus another money savings area.

However, the greatest advantage of DMT is the contribution of mission rehearsal. Prior to a deployment, a humanitarian operation, or even a limited to full scale conflict, crews can go to the simulator and practice the mission they are going to fly. If a C-5 crew wants to practice approaches into Somalia, or if a B-1 crew wants to practice a bomb run into Libya, the capabilities of DMT enable crews to practice the actual mission before they "have to do it for real". Even more complex training can occur if two B-1 crews in cell formation needed to practice a bombing mission, prior to the actual mission. Add in their air refueling with a KC-135 (either simulated or by a 135 simulator actually being flown at the same time) and you can see not only the flying cost savings, but 
improved training capabilities. The realism of the mission is provided by the capability to send a satellite over a desired area, take photos, download them into the data base, and then have the updated actual environment for the crews to practice in. By having the ability to practice those wartime missions in the exact area, is a tremendous advantage. Whether it is the decrease in anxiety because the crew is in familiar territory or the advantage of practicing different techniques to see which ones work and which ones don't allows the warfighter an advantage that his enemy doesn't. The advantage of experiencing the fog and friction of war, before it really happens would be invaluable. In a time of limited budgets, the U.S. military needs to use every advantage possible to ensure our crews are properly trained for the next conflict. 


\section{Chapter 7}

\section{Conclusions}

In conclusion, the mandate of all DoD simulators to be HLA compliant, which produces DMT, is a very controversial one. While the vision of Gen. Fogleman was to find the very best way to keep our crews trained efficiently, the services are left to find the money to pay for this vision. All of DoD has to weigh the advantages and disadvantages of DMT, and determine the best course of action at a time where money is tight.

There are numerous obstacles for AMC to overcome before they can fully implement DMT. First, finding a $\$ 175$ million to convert the simulators in an already under-funded budget, is required. However, even if funding was identified, some technological breakthroughs are still needed. Those obstacles include finding solutions and alternatives to the physical limits found in the phone lines used today. Latency between simulators is a problem yet to be solved. Security of the RTI network used to interfaces simulators is even a larger issue. The military is not going to perform operations that may give away national security secrets. Finally, if all the physical limits are overcome, there still remains reluctance with pilots who may or may not understand the capabilities that this new technology brings to simulators. 
There are also numerous benefits that can be gained from DMT. While it is true that DMT costs a lot, it will save more money in the long run, through reduced flying time. More importantly, crewmembers will be able to get more and better training in less time. This will allow our crewmembers to keep the superiority we enjoy today by improving our training. The advantage of mission rehearsal contributes to this better training. The idea that the DMT simulator can give an accurate and exact replica of any terrain anywhere in the world for crewmembers to train in provides for the most realistic training ever experienced. The practicing of techniques and procedures to determine which ones actually work and don't work will result in lives saved. Imagine how improved our crew's performance could have been during the Libyan bombing raid if they could have practiced their mission prior to the actual execution.

In conclusion, to not support DMT with any funding is a serious mistake on the part of AMC for two reasons. First, there is little evidence that consideration was given to "Moore's Law", named after Gordon Moore chairman of Intel Corp. He has found that data storage of a microchip will double every 18 months at the same price. Not only has this been true for the last 30 years, but Moore expects it to be true for the next 20 years. The decision to not fund DMT was made in the spring of 1998. This was reflected in the FY00 POM, which involves the years 2000 through 2005. In the next 2 to 7 years time frame, technology will have doubled 5 times. Some of the obstacles will be solved during that time frame.

Second, the biggest advantage to DMT is mission rehearsal. The ability to practice combat missions in an exact replicated environment will reduce the fog and friction 
found in war. If this program can save lives, through better training, it will pay for itself many times over. 


\section{Glossary}

$\begin{array}{ll}\text { AC } & \text { Aircraft Commander } \\ \text { ACC } & \text { Air Combat Command } \\ \text { ACES } & \text { Air Force Command Exercise System } \\ \text { ACSC } & \text { Air Command and Staff College } \\ \text { AFCAIG } & \text { Air Force Cost Analysis Improvement Group } \\ \text { AMC } & \text { Air Mobility Command } \\ \text { AMC/DOT } & \text { AMC Director for Operations and Training } \\ \text { AMC/FMBT } & \text { AMC Financial Management and Budget } \\ \text { A/R } & \text { Air Refueling } \\ \text { CP } & \text { Copilot } \\ \text { DMSO } & \text { Defense Modeling and Simulations Office } \\ \text { DMT } & \text { Distributive Mission Training } \\ \text { DOD } & \text { Department of Defense } \\ \text { EXCIMS } & \text { Executive Council for Modeling and Simulation } \\ \text { FAA } & \text { Federal Aviation Administration } \\ \text { FAR } & \text { Formation Air Refueling } \\ \text { HLA } & \text { High Level Architecture } \\ \text { ISDN } & \text { Integrated Services Digital Network } \\ \text { JA/ATT } & \text { Joint Airborne/Airtransportability Training } \\ \text { KBPS } & \text { Kilobits per second } \\ \text { OMT } & \text { Object Model Template } \\ \text { ORI } & \text { Operational Readiness Inspection } \\ \text { PAA } & \text { Primary Aircraft Assigned } \\ \text { PBD } & \text { Program Budget Decision } \\ \text { PEM } & \text { Program Element Monitor } \\ \text { POM } & \text { Program Object Memorandum } \\ \text { PPBS } & \text { Planning, Programming, and Budgeting System } \\ \text { RTI } & \text { Run Time Infrastructure } \\ \text { SAAM } & \text { Special Assignment Airlift Mission } \\ \text { SOL II } & \text { Special Operations Low Level } \\ \text { SOW } & \text { Statement of Work } \\ \text { T/O } & \text { Takeoff } \\ \text { TTF } & \text { Training, Test and Ferry } \\ \text { TWCF } & \text { Transportation Working Capitol Fund } \\ & \end{array}$




\section{Bibliography}

Fogleman, Ron, Gen. Revolutionizing Training. Washington, D.C.: USAF Chief of Staff Message, 1996.

Kaminski, Paul. High Level Architecture Simulators. Washington, D.C.: Undersecretary of Defense for Acquisition and Technology, 1996.

Olsen, Kenneth, Maj. Air Mobility Command Flying Time Models, Scott AFB, IL: HQ AMC/DOTR Chief flying time manager's program for FY 00-05, 1998.

Nunn, Mark, Maj. FY00-05 POM for Program Element 41897. Scott AFB, IL: HQ AMC/DOTR Chief of Aircrew Training Devices, 1998.

Kross, Walter, Gen. MCI 36-22XX, Scott AFB, IL: HQ AMC, 1998.

Perry, William. Department of Defense Directive 5000.59. Washington D.C.: Deputy Secretary of Defense direction, 1994.

Simulator Interoperability Standards Organization. HLA Rules Version 1.3. New York 1998. City, NY.: DOD guidance from the Electrical and Electronics Engineers Inc,

FAA Advisory Circular 120-46A. Use of Airplane Flight Training Devices. National Flight Simulator Program Manager's qualification standards, 1994.

Defense Advanced Research Project Agency. STOW - Synthetic Theater of War. http://web-ext2.darpa.mil/iso/stow/. 1998.

AMC Simulators. Distributive Mission Training. http://140.175.188.129/cfdocs/orangebook/selectionpage.cfm 1998.

Joint Advanced Distributed Simulation, The Gateway to Reality. http://www.jads.abq.com// 1998.

Defense Modeling and Simulation Office, Glossary of Modeling and Simulation Term. http://www.dmso.mil/docslib/mspolicy/glossary/glossary.html. 1998. 


\title{
DISTRIBUTION A:
}

Approved for public release; distribution is unlimited.

\author{
Air Command and Staff College \\ Maxwell AFB, Al 36112
}

